\title{
An Overview of Student Engagement With Written Feedback in EFL Writing Class
}

\author{
Hanh Thi My Nguyen ${ }^{1 *}$ \\ ${ }^{1}$ Tien Giang University, Tien Giang Province, Viet Nam \\ *Corresponding author.Email: nguyenthimyhanh@tgu.edu.vn
}

\begin{abstract}
Student engagement with written feedback plays an essential role in EFL writing classes. This topic has drawn the growing attention of many researchers as well as instructors teaching English writing worldwide. The current study was conducted to summarize the main aspects relating to student engagement with written feedback. Based on referring to previous research, the current research findings indicated that various studies focused on how students engaged affectively, cognitively, and behaviorally with feedback activity. Moreover, few studies employed data collection instruments for quantitative analysis in terms of data collection instruments. Instead, they paid more attention to qualitative data instruments such as interviews, students' written texts, teacher and peer written feedback, retrospective protocols, etc. Also, the studies are mainly based on feedback receivers' perspectives. Many researchers frequently chose a small sample size. Therefore, further studies in different contexts with the use of data collection instruments for quantitative and qualitative data, different perspectives of feedback receivers and givers, sample size, factors affecting student engagement, and a longer period of time are recommended to be conducted for deeper understandings of student engagement with types of written feedback in English writing class.
\end{abstract}

Keywords: peer written feedback, student engagement, teacher written feedback.

\section{INTRODUCTION}

In recent years, student engagement has gradually drawn researchers' attention in the field of L2 or EFL teaching and learning because of its vital roles in the English language learning process and the development of learning outcomes. A lot of research has indicated a close relationship between student engagement and students' learning outcomes [1-3]. The essential roles of student engagement in written feedback provided by teachers and peers have also been emphasized in EFL writing classes.

Feedback is considered one of the most important parts of educational settings [4]. In the context of writing classrooms, it raises students' awareness about how they perform in their written texts and then making some changes to improve their writing quality. When a teacher offers written feedback to students' writings, it is meaningful support since it guides them in their writing, enhancing L2 or EFL learners' writing ability. English writing teachers must provide effective feedback [5], supporting the improvement of the texts written by learners [6-8]. Moreover, peer feedback is considered an essential factor because it improves their writing skills [9]. Feedback has been considered a factor that greatly affects students' achievement. It facilitates students' cognition, pointed out their strong points and weak points, and offers judgment for feedback receivers [10]. However, in feedback activities, there are various factors as mediating variables that help promote writing products' outcomes. Among them, student engagement is an essential element. Numerous instructors around the world pay attention to fostering students' engagement in their learning process [11-13]. Ellis [14] states that student engagement plays an important part as a mediator for grammatical corrections from teachers and learners' performances in terms of written feedback on forms.

According to Ellis [14], student engagement plays a vital part in the educational process. Several student engagement studies with teacher written feedback [1518] were conducted. In terms of students' engagement with peer feedback, few papers of student engagement with peer-written feedback and their revisions have been examined. In short, student engagement with written feedback provided by teachers or peers has been carried out by researchers and L2 or EFL writing instructors with some significant findings. However, the ways students engage with written feedback from writing instructors and their peers in different settings, as well as the relationship between student engagement in written feedback provided by instructors, peers, and 
their revisions, factors affecting student engagement still need further research to provide deeper understandings in the aspects of the engagement of learners with feedback in written forms from peers and teachers. The current study was carried out to review the research relating to students' engagement with written feedback provided by teachers and peers from 2018 to 2020 . This might help researchers have an overview and conduct more studies of this topic to get deeper understandings of student engagement with written feedback offered by their instructors and peers, fostering EFL learners' writing ability.

\section{LITERATURE REVIEW}

\subsection{Concepts}

\subsubsection{Student engagement}

\subsubsection{Definition of student engagement}

There have been various definitions of student engagement by different educational researchers and instructors worldwide. It is a complex construct with a number of notions. According to Finn [19], student engagement consists of behavior that is about students' obedience to school regulations, actions based on their teachers' instructions and assignment accomplishment, and affection that involves school and study emotions. Another definition is defined by Fredricks et al. [1] as the concept containing three factors: behavioral engagement, emotional or affective engagement, and cognitive engagement.

\subsubsection{Benefits of student engagement}

The essential roles of student engagement have increasingly drawn various researchers' attention [20]. Student engagement has a strong relationship with achievement [21], and there is the association between engagement and the improvement in academic results in the research literature [22]. [23] emphasized the essential role of affection as an element of engagement among the students in their case study which was affected by the students' attitudes, beliefs, and goals.

\subsubsection{Feedback}

\subsubsection{Definition of feedback}

According to Keh [24], feedback is the input from a reader to a writer, which offers beneficial information, usually in comments, inquiry or recommendations to the writer to make some possible changes in their writing texts. Moreover, [25] emphasizes that feedback refers to writing extensive comments on writers' writing products to give a reader response to students' texts, which enables them to make progress in their writing texts and learn as writers. In summary, feedback is considered as a fundamental element in a writing process in which readers' comments, questions, and suggestions are offered to writers as the useful guides for better writing products and the improvement of writers' writing skills.

\subsubsection{Definitions of teacher written feedback and peer} written feedback

Mack [26] states that teacher written feedback refers to written comments, types of questions, and adjustment of mistakes on students' writing products. It can be in different types such as questions, error corrections, praises, recommendations, criticisms, and so on. Furthermore, [4] consider teacher written feedback as a medium for teachers to offer students' responses and advice, enhancing students' improvement. In short, the teacher provides written feedback to make their students read and understand their issues and employ it for some possible changes in order to enhance their written texts. In terms of peer feedback, it refers to a student's comments on another's writing text in written or oral forms via active engagement with various drafts, which has been considered a common element in processoriented writing class [27]. However, with the time limitations as well as other factors, in the current study, only peer feedback in written form was employed and discussed.

\subsubsection{Student engagement with written feedback from teachers and peers}

Student engagement referred to the "meta-construct" of three elements relating to behavior, cognition, and affection [20.1.28]. In Swain's point of view [29], the researcher indicates that "the relationship between cognition and emotion is, minimally, interdependent; maximally, they are inseparable/ integrated" (p. 196). In addition, engagement also promotes students to devote their cognition to accept or retain the given feedback [30]. Figure 1 presented student engagement framework with written corrective feedback (WCF) given by teachers.
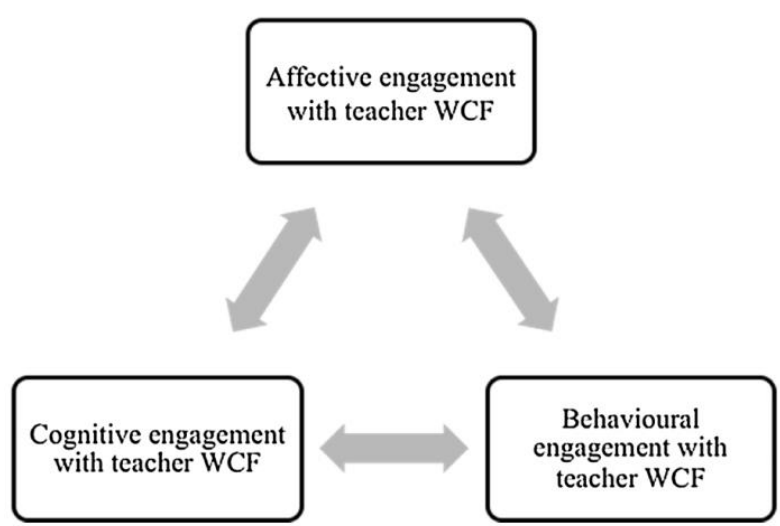

Figure 1 Framework of student engagement with written corrective feedback from teachers [15]

\subsection{Previous studies}

There have been several studies of students' engagement with written feedback. The research related to student engagement, teacher and peer written feedback were mentioned in Table 1. Some studies of student engagement with written feedback from instructors were conducted. [15] investigated student 
engagement with written feedback from teachers that focused on grammatical errors at a Chinese institution with the participation of L2 lower-proficiency females in three weeks. The data collection instruments were essay drafts, written feedback from the teacher, immediate verbal reports for students, and semistructured interviews. The paper showed students' relatively positive affective engagement. Nevertheless, students showed little consciousness in understanding the written corrective feedback, typically indirect. Furthermore, low proficiency in English might negatively impact cognitive and behavioral engagement and balances of the sub-factors, namely affective, behavior, and cognition. Several limitations are the participation of lower-proficiency students instead of other levels, one feedback-revision cycle, and the focus on written corrective feedback, but not feedback on content and organization.

Zheng et al. [18] investigated student engagement with the feedback from the supervisor for the master's thesis with three participants who were in their second year. The data were collected from the written drafts with feedback, verbal reports from supervisors, and students' interviews. Six aspects of student engagement were finally recognized. Student engagement had subdimensions that were interrelated with one another. The behavioral engagement was the most observable dimension, and teachers should know how their students react in terms of affective and cognitive factors. Some limits focus on supervisors and students in China and only examine how the students engaged with feedback from supervisors. Thus, other contexts or the combination of feedback receivers and givers should be carried out.

By studying two L2 high-proficiency students who were Ph.D. students of a Chinese university with the use of qualitative data collected from interviews, the use of stimulated recalls, drafts of different stages, and response letter drafts, Yu and Jiang [31] indicated that there were complicated and dynamic links among affective, behavioral and cognitive elements. In addition, the features of feedback and the experience of investigators greatly influenced the affective aspects of new researchers. Affective and behavioral factors were inconsistent because of an implicit issue of dealing with reviewers' feedback under academic publishing pressure. Several limits included just two participants and no investigation of reviewers' perceptions.

Furthermore, enhancing students' engagement with feedback from instructors via the use of rebuttals was conducted by Man et al. [32]. The research took place in a university in China with 118 first-year participants. Collected data were from structured questionnaires, retrospective interviews, and first and revised drafts. The findings indicated when the students revised their writings, they tended to get little interest in spending time as well as attempt writing the rebuttals. Nevertheless, they immensely liked such activities in the case of being more acquainted with them or realizing the task's usefulness. Student engagement can be enhanced via rebuttal writing.

Moreover, the employment of FEET to help promote learners' engagement with feedback activity was implemented by Van der Keij [33]. This study carried out in Australia. There were 23 participants whose ages were from 13 to 14 years old. The instruments for gathering data comprised interviewing teachers, using focus groups of students, and analyzing FEET booklet materials. The paper's findings indicated the students' positiveness in the employment of FEET, enabling them to engage with FEET. The paper's findings were few participants took part in only three weeks. Further studies should focus more on how to make learners overcome the negativeness of emotions.

Zhang and Hyland [16] examined students' engagement with the feedback from instructors and automated comments in 16 weeks. In the study, two third-year Chinese students were chosen. Data were collected via student texts, automatic writing evaluation feedback, teacher feedback, semi-structured interviews, and documents. The results found out good points and disadvantages of these sorts of feedback and indicated engagement as an essential mediator, fostering writing improvement. However, there were only two participants instead of more learners to explore engagement patterns.

In Tian and Zhou's [34] research, student engagement with feedback from their instructor and peer and automated feedback in an online class of writing was carried out. Five Chinese students participated in 17 weeks. Data were collected from textual data and interviews. The findings were students' dynamic and reciprocal engagement with three kinds of feedback, supported by various personal and contextual elements, affecting students' uptake of feedback. Nevertheless, further studies should compare synchronous as well as asynchronous feedback given by instructors and peers.

Unlike Tian and Zhou's [34] study, [17] investigated student engagement with peer feedback among three Chinese students in the second year of a master's program in Macau university. The instruments for gathering data consisted of interviews with semistructured stimulated recalls, online interviews, first, revised drafts and finalized written texts, written feedback given by peers, and recordings of verbal conferences for feedback from peers. The research revealed dynamic and complicated interconnections of the constructs in each component of engagement as well as within three engagement components. Plus, three participants manifested personal dissimilarities related to engagement. The affective factor might enhance or had negative effects on the engagement of behavior and cognition. The study's restrictions are the small sample size, the focus on qualitative data, only analyzing peer feedback from feedback receivers' views. 
Table 1 A list of previous research

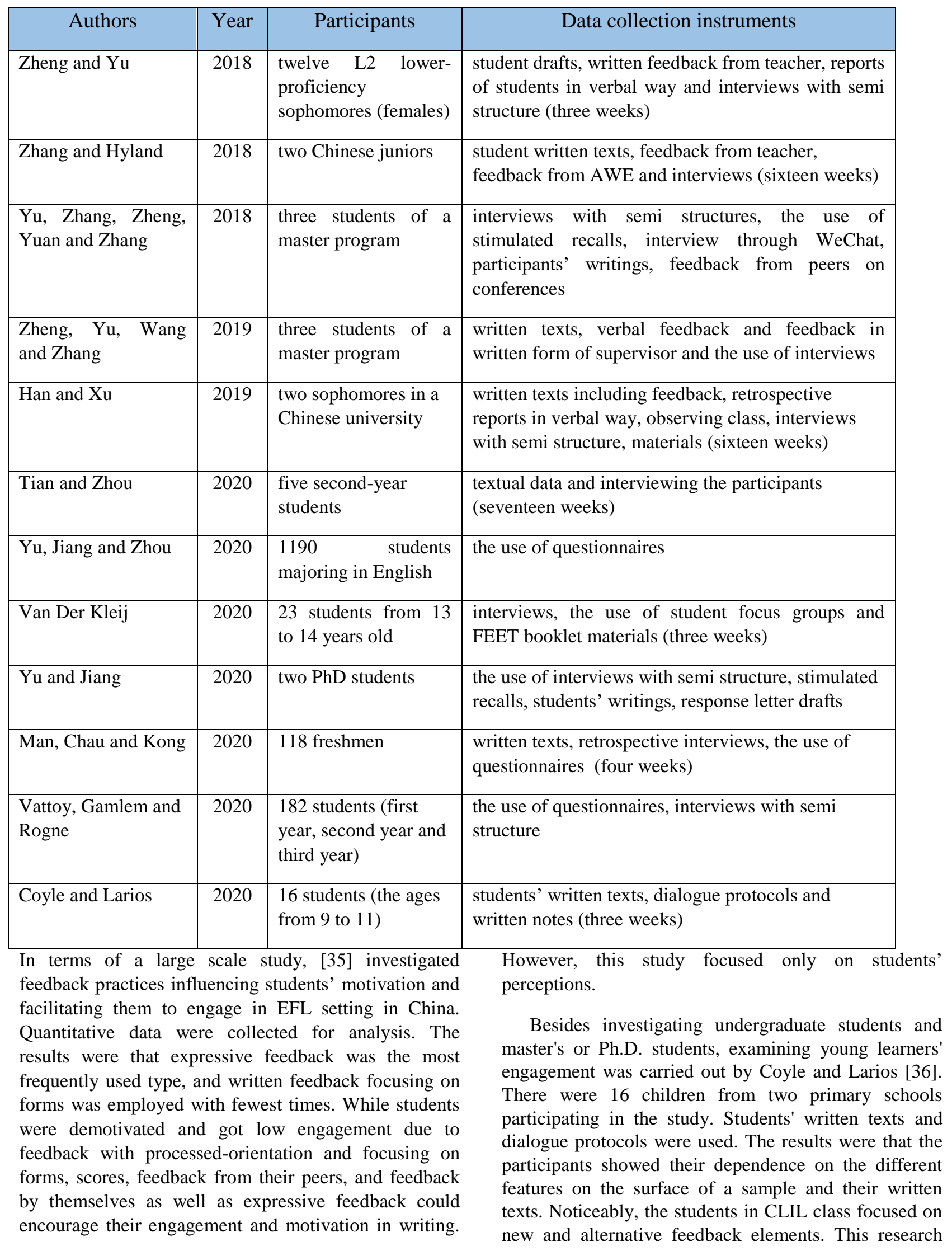


showed more details of the ways children learning English as a second language engaged with a teaching technique as well as the emphasis of the role of settings in feedback research. A few limits are small-scale, less encouragement from parents, and no data from questionnaires and interviews.

[37] examined students' knowledge of feedback and their engagement with this activity. The research was conducted with two participants in a university in China. Data were collected from collecting students' writing products, including feedback in written form, interviewing each participant with semi-structured, using retrospective verbal reports, observing their class, and gathering some documents. The results were that students' feedback literacy consisted of various aspects such as capacity of cognition, capacity of socialaffective aspect, and social-affective disposition. These parts differed among individuals and even the within each of the participants. This recommended feedback literacy's emergent features and characteristics of situations. The level of engagement might be reduced because of the three factors' unbalance. The study's limits are a small sample size and qualitative data.

In Vattoy et al.'s [38] study, the engagement of the students with feedback activity and assessment was examined with the use of qualitative and quantitative data. This study occurred in a tertiary institution in Norway, and 128 students participated in the research. Questionnaires and interviews were employed. The result emphasized the most fundamental components were influencing the employment of feedback among students consisted of the sum of attempt and qualitative traits of feedback. The study revealed that feedback quality was a stronger predictor for female students' use of feedback. The employment of feedback and qualitative features of feedback were related to each other via the partial mediation of feedback quantity. The students who were interviewed stated that intelligibility, process orientation, and interaction need to be included in the feedback activity. Feedback barriers were due to the feedback that consisted of negative elements and lacked comprehensibility or contradiction and irrelevance. The participants employed maladaptive feedback agency when the instructor and students had distrust, negativeness, or no agreements. The study also revealed the assessment in a summative way, which comprised formative features. A few limitations are only the context of a university in Norway and some limits of the questionnaire.

\section{DISCUSSIONS}

With the vital role of students' engagement with the feedback in written form, many studies of students' engagement, peer-written feedback, and teacher written feedback have been carried out by various researchers and instructors from different countries around the world.

The first noticeable point was that most of the studies relating to student engagement, peer-written feedback, and teacher-written feedback were conducted with qualitative data (e.g., [15] [17] [31] [37]). Common data collection instruments like semi-structured interviews, stimulated recalls, student immediate oral reports, teacher and peer-written feedback, students' revised drafts, and observations. Besides, there was little research with the use of the mixed method. For instance, [32] collected data from structured questionnaires, first and revised written texts, retrospective interviews in the study of enhancing the engagement of students with the feedback offered by instructors with the use of writing rebuttals. Similarly, [38] carried out students' feedback engagement and assessment experiences by using a mixed-method. The study's data collection instruments were questionnaires and interviews.

Second, various studies examined students' engagement in terms of cognitive, behavioral, and affective aspects from the perspective of feedback receivers instead of feedback givers like teachers or peers. A typical example was the research conducted by $\mathrm{Yu}$ et al. [35], which investigated practices of feedback that helped promote the motivation of students in writing and their engagement in China. One of the limitations presented in the study was that the researchers studied the variables in the perspective of students. Its suggestion for further studies was incorporating both teacher and students' perceptions. [17] also recommended further research with the viewpoint of the participants giving feedback to their peers.

Third, a small sample size was common among student engagement studies and written feedback, especially in research that employed a qualitative approach. [16] indicated that further studies should explore students' engagement with various participants. In addition, [31] emphasized that with only two participants in a Chinese tertiary institution, the research's results may not be generalized in different contexts. On the contrary, the numbers of students in some research with quantitative data were quite large, like 118 students [32], 1190 students [35].

Finally, some issues relating to different aspects of feedback instead of focusing on written corrective feedback, types of feedback, and longitudinal studies were suggested to be carried out in future research for comprehensive understandings of students' engagement with feedback in written forms from peers and instructors.

\section{CONCLUSIONS}

Students' engagement is essential in enhancing EFL students' writing ability. It is drawing more and more attention from researchers and instructors in different 
countries. In general, various previous studies found out how students engage affectively, behaviorally, and cognitively. However, there are still several main aspects relating to student engagement with written feedback that needs further research for deeper understanding, such as data collection instruments for quantitative and qualitative data, the combination of perspectives' of feedback receivers and givers, factors influencing the engagement of students with feedback in the written form provided by instructors and peers, sample size as well as time for conducting a study.

\section{REFERENCES}

[1] J.A. Fredricks, P.C. Blumenfeld, A.H. Paris, School engagement: Potential of the concept, state of the evidence. Review of Educational Research, 74, 2004, 59-109.

[2] E.R. Kahu, Framing student engagement in higher education. Studies in Higher Education, 38(5) (2013) 758-773.

[3] N. Zepke, L. Leach, P. Butler, Engagement in post-compulsory education: Students' motivation and action. Research in Post-Compulsory Education, 15 (2010) 1-17.

[4] K. Hyland, F. Hyland, Feedback on second language students' writing. Language Teaching, 39 (2006) 83-101.

[5] F. Hyland, K. Hyland, Sugaring the pill: Praise and criticism in written feedback. Journal of Second Language Writing, 10 (2001) 185- 212.

[6] D.R. Ferris, Does error feedback help student writers? New evidence on the short- and long-term effects of error correction. In K. Hyland \& F. Hyland (Eds.), Feedback in Second Language Writing: Contexts and Issues Cambridge: Cambridge University Press, 2006, pp. 81-104.

[7] D.R. Ferris, B. Robinson, Error feedback in L2 writing classes. How explicit does it need to be? Journal of Second Language Writing, 10, 2001, 161-184.

[8] J. Goldstein, Making sense of distributed leadership: The case of peer assistance and review, Educational Evaluation and Policy Analysis 26(2) (2004) 173-197.

[9] M. Farrah, The impact of peer feedback on improving the writing skills among Hebron university students, An-Najah University Journal for Research, 26(1) (2012), 179-210.

[10] K. Hyland, Faculty feedback: Perceptions and practices in L2 disciplinary writing. Journal of Second Language Writing, 22 (2013) 240-253.

[11] J. Harmer, How to Teach English, Harlow, Essex: Pearson Education, 2007.
[12] S. Kearney, Improving Engagement: The use of "Authentic self-and peer-assessment for learning" to enhance the student learning experience. assessment \& evaluation in higher education, 38(7) (2013) 875-891.

[13] J.C.K. Junior, Analysing the effectiveness of engagement-Promoting techniques in the EFL classroom. International Journal of Learning, Teaching and Educational Research, 10(1) (2015) 80-92.

[14] R. Ellis. A framework for investigating oral and written corrective feedback, Studies in Second Language Acquisition, 32 (2010) 335-349.

[15] Y. Zheng, S. Yu, Student engagement with teacher written corrective feedback in EFL writing: A Case Study of Chinese Lower-Proficiency Students. Assessing Writing, 37 (2018) 13-24.

[16] Z. Zhang, K. Hyland, Student engagement with teacher and automated feedback on L2 writing. Assessing Writing, 36 (2018) 90-102.

[17] S. Yu, Y. Zhang, Y. Zheng, K. Yuan, L. Zhang, Understanding student engagement with peer feedback on master's theses: a Macau study. Assessment \& Evaluation in Higher Education (2018) 1-16.

[18] Y. Zheng, S. Yu, B. Wang, Y. Zhang, Exploring student engagement with supervisor feedback on master's thesis: Insights from a case study. Innovations in Education and Teaching International (2019) 1-12.

[19] J.D. Finn, Withdrawing from school, Review of Educational Research 59(2) (1989) 117-142.

[20] J.J. Appleton, S.L. Christenson, M.J. Furlong, Student engagement with school: Critical conceptual and methodological issues of the construct, Psychology in the Schools 45(5) (2008) 369-386.

[21] J.T. Guthrie, Contexts for engagement and motivation in reading, Reading Online, 4(8) (2001).

[22] J. Fredericks, P. Blumnfeld, J. Friedel, A. Paris, In School Engagement, Indicators of Positive Development Conference. Washington, DC, 2003.

[23] N. Storch, G. Wigglesworth, Learners' processing, uptake, and retention of corrective feedback on writing. Studies in Second Language Acquisition, 32 (2010) 303-334.

[24] C.L. Keh, Feedback in the writing process: A model and methods for implementation. ELT Journal, 44(4) (1990) 294-304.

[25] K. Hyland, Second Language Writing. Cambridge: Cambridge University Press, 2003. 
[26] L. Mack, Issues and Dilemmas: What conditions are necessary for effective teacher written feedback for ESL learners? Polyglossia, 16 (2009) 33-39.

[27] Stanley, G. (2011). Approaches to process writing. Retrieved July 4, 2011, from http://www.teachingenglish.org.uk/think/articles/a pproaches-process-writing

[28] M-T. Wang, J.B. Willett, J.S. Eccles, The assessment of school engagement: Examining dimensionality and measurement invariance by gender and race/ethnicity. Journal of School Psychology, 49(4) (2011) 465-480.

[29] M. Swain, The inseparability of cognition and emotion in second language learning. Language Teaching, 46 (2013) 195-207.

[30] R. Sachs, C. Polio, Learners' uses of two types of written feedback on an L2 writing revision task. Studies in Second Language Acquisition, 29 (2007) 67-100.

[31] S. Yu, L. Jiang, Doctoral students' engagement with journal reviewers' feedback on academic writing. Studies in Continuing Education (2020) $1-18$.

[32] D. Man, M.H. Chau, B. Kong, Promoting student engagement with teacher feedback through rebuttal writing. Educational Psychology (2020) $1-19$.

[33] F.M. Van der Keij, Evaluation of the "Feedback engagement enhancement tool's to examine and enhance students' engagement with feedback on their writing. Studies in Educational Evaluation, 60 (2020) 1-12.

[34] L. Tian, Y. Zhou, Learner engagement with automated feedback, peer feedback and teacher feedback in an online EFL writing context. System (2020).

[35] S. Yu, L. Jiang, N. Zhou, Investigating what feedback practices contribute to students' writing motivation and engagement in Chinese EFL context: A large scale study. Assessing Writing (2020).

[36] Y. Coyle, J. Roca de Larios, Exploring young learners' engagement with models as a written corrective technique in EFL and CLIL settings, System (2020).

[37] Y. Han, Y. Xu, Student feedback literacy and engagement with feedback: A case study of Chinese undergraduate students, Teaching in Higher Education (2019) 1-16.

[38] K.D. Vattøy, S.M. Gamlem, W.M. Rogne, Examining students' feedback engagement and assessment experiences: a mixed study. Studies in Higher Education (2020) 1-13. 